Research Article

Journal of Extension Education

Vol. 31 No. 4, 2019

DOI:https://doi.org/10.26725/JEE.2019.4.31.6381-6385

\title{
Performance Analysis of Vocational Higher Secondary Education (VHSE) Agricultural Teachers in Kerala
}

\author{
Chhanda Charana Mahananda ${ }^{1}$ and G.S. Sreedaya ${ }^{2}$
}

\begin{abstract}
The study was conducted in three zones of Kerala during 2017-2019 to analyze the job performance of the Vocational Higher Secondary Education (VHSE) Agricultural teachers and to find out the relationship between their profile characteristics and their job performance level. Altogether, 120 VHSE agricultural teachers from three zones of Kerala namely, Northern zone, Central zone and Southern zone, formed the sample. The study revealed that training had a positive and significant relationship with job performance and with organizational climate. Age on the other hand had a negative correlation with job performance.
\end{abstract}

Keywords: Job Performance; Vocational Education; Agricultural Teachers; Training; Organizational climate; Kerala

\section{INTRODUCTION}

In Kerala, the vocational education in Agriculture is mainly focused on developing skill, abilities, knowledge and personality of the students to make them employable and self-employed in Agricultural and allied sector. It can be achieved by increasing the efficiency of the VHSE (Vocational Higher Secondary Education) Agricultural teachers and by creating awareness about VHSE among the people in the state. Job performance and quality of the employee are the important components for the effectiveness of an organization. According to Getzels (1958), the function of both role and character is the performance of an individual. An individual's role attitude in any organization will be good if the prospects of role and personality arrangements are consistent. Employees should have a high-level job performance, strong mental abilities and skills, knowledge on subject matter, work interest, excellent personality and interpersonal relationship with all members of the organization to achieve the organizational objective. Hence, for increasing the effectiveness of the VHSE School, a high level of job performance and qualities of teachers are needed.

All these can be attained by the human resource management of the organization (school), since teaching is multifaceted and

1 PG Scholar and ${ }^{2}$ Assistant Professor, Department of Agricultural Extension, College of Agriculture, Kerala Agricultural University, Vellayani, Kerala 
need varieties of human traits and abilities such as teachers' mental abilities and skills, their knowledge of the subject matter, personality, beliefs, attitude, interest and relationship with students, colleagues and all members of the school. Accordingly this study was taken up.

\section{METHODOLOGY}

The study was confined to the three zones of Kerala viz., Northern, Central and Southern. Primary data were collected using a structured pre-tested interview schedule and multi stage sampling was done to identify the respondents. In the first stage, three districts each were selected from the three zones, i.e., Kasaragod, Kozhikode, Malappuram from the Northern zone; Palakkad, Thrissur, Ernakulam from the Central zone and Thiruvananthapuram, Kollam, Kottayam were selected from the Southern zone, considering the number of VHSE Agricultural teachers available in the VHSE schools in these nine districts. A total of 120 available vocational course teachers in agriculture and allied sector were selected from the above-mentioned districts by using systematic random sampling. Ex-post-facto research design was followed in the present study, since the phenomenon had already occurred. The job performance of the VHSE Agricultural teachers was evaluated with the help of the scale created by Sundaraswamy (1987). The scale comprised seven positive statements and has been rated on a three-point continuum, viz. most efficient, efficient and least efficient with scores of 3, 2 and 1 respectively. The minimum and maximum scores for this scale were 7 and 21 , respectively. The scores of all the statements were summed up to get the job performance scores of respondents. The organizational characteristics was measured by using the scale developed by Kolb et al., (1974). The scale consisted of seven statements of which six are positive statements and one is negative statement. The statements were rated over a five-point continuum namely strongly agree, agree, undecided, disagree and strongly disagree with scores of 5, 4, 3, 2 and 1 respectively for positive statements and reversed scoring for the negative statements. The score of each statement were added to get the score of organizational climate. The possible scores ranged from 7 to 35 . The profile characteristics of the teachers such as age, gender, educational level, training received, job experience and organizational climate were categorized and expressed in terms of frequency and percentage. The correlation between the profile characteristics and job performance were worked out at $1 \%$ and $5 \%$ level of significance.

\section{FINDINGS AND DISCUSSION}

The results of the study revealed that majority of the teachers (95.83\%) belonged to the middle age category and 72.5 per cent of them were females. Furthermore, it was found that 59.17 per cent of teachers were having a master's educational qualification, majority of the teachers (76\%) belonged to the average (8-14 years) job experience category and more than half (55.83\%) of teachers belonged to a low-trained (3-13 days) group. It was also observed that 60 per cent of the teachers felt that their schools had a good organizational climate, which might be due to the good 
Performance Analysis of Vocational Higher Secondary Education (VHSE)

Agricultural Teachers in Kerala

Table 1.

Profile of VHSE Agricultural Teachers

$(n=120)$

\begin{tabular}{|c|c|c|c|c|c|}
\hline SI. No. & Variable & Category & Class Interval & Frequency & Percentage \\
\hline \multirow{3}{*}{1.} & \multirow{3}{*}{ Age } & Young & $<35$ & 5 & 4.17 \\
\hline & & Middle & 35 to 55 & 115 & 95.83 \\
\hline & & Old & $>55$ & 0 & 0 \\
\hline \multirow{2}{*}{2.} & \multirow{2}{*}{ Gender } & Male & - & 33 & 27.50 \\
\hline & & Female & - & 87 & 72.50 \\
\hline \multirow{3}{*}{3.} & \multirow{3}{*}{$\begin{array}{ll}\text { Educational level } \\
\text { (degree) }\end{array}$} & Bachelor & - & 32 & 26.67 \\
\hline & & Master & - & 71 & 59.17 \\
\hline & & PhD & - & 17 & 14.16 \\
\hline \multirow{3}{*}{4.} & \multirow{3}{*}{ Job experience } & Less & 1-7 & 12 & 10 \\
\hline & & \begin{tabular}{|l|} 
Average \\
\end{tabular} & 8-14 & 91 & 76 \\
\hline & & High & $15-21$ & 17 & 14 \\
\hline \multirow{3}{*}{5.} & \multirow{3}{*}{ Training received } & Low & $3-13$ & 67 & 55.83 \\
\hline & & Average & $14-24$ & 38 & 31.67 \\
\hline & & High & $25-36$ & 15 & 12.50 \\
\hline \multirow{3}{*}{6.} & \multirow{3}{*}{ Organizational climate } & Poor & $7-16$ & 0 & 0 \\
\hline & & Average & $17-26$ & 48 & 40.00 \\
\hline & & Good & $27-36$ & 72 & 60.00 \\
\hline
\end{tabular}

organizational policies and relationship among the members of the school.

The probable reason for better results in the school are due to 95.83 per cent of teachers were in young age group and most of them i.e., 76 per cent had good job experience (8-14 years). This might be due to the expansion of VHSE schools and courses in Kerala during 1995-96 and 2000-01, which was the highest, i.e., 389 schools and 1100 batches, which resulted in mass recruitment in that period of time. Furthermore, majority (72.50\%) of teachers were female and more than half $(59.17 \%)$ had a master's degree as their educational level. Kerala is far ahead in all social development indicators having a literacy rate of 93.91 per cent, high sex ratio (1084 females per 1000 males), promoting woman education and empowerment. This might be the reason for 59.17 per cent teachers had a master's degree and 14.16 per cent had a PhD. degree and 72.50 per cent of teachers were female. There was lack of advance training for teachers 55.83 per cent of teachers in low trained category. It was observed that half of the teachers (50.00 \%) had a high level of job 
Table 2.

Job Performance Level of VHSE Agricultural Teachers

$(n=120)$

\begin{tabular}{|c|l|c|c|c|}
\hline SI. No. & \multicolumn{1}{|c|}{ Category } & Class Interval & Frequency & Percentage \\
\hline 1. & Low & $7-11$ & 6 & 5 \\
\hline 2. & Medium & $12-16$ & 54 & 45 \\
\hline 3. & High & $17-21$ & 60 & 50 \\
\hline
\end{tabular}

performance whereas remaining 5.00 per cent and 45.00 per cent had a low and medium level of perception respectively.

Furthermore, the correlation analysis showed that there was a positive and significant correlation between training received and organizational climate with the job performance of the teachers. It was also found that there was a negative correlation between age and job performance of teachers. performance of teachers. The probable reason for the result might be due to the statistic that most of old aged teachers felt more organizational stress, handling pressure, and lack in physical strength and energy than the young and middle-aged teachers. It was found that the high training received category teachers had a high job experience compared with the low and average training received teachers and also the Pearson correlation coefficient value showed that training earned

Table 3.

Correlation between the Profile and Job Performance of the VHSE Agricultural Teachers

$(n=120)$

\begin{tabular}{|c|l|c|}
\hline Sl. No. & \multicolumn{1}{|c|}{ Items } & Coefficient of Correlation 'r' Values \\
\hline 1. & Age & $-0.210^{*}$ \\
\hline 2. & Gender & $0.101 \mathrm{NS}$ \\
\hline 3. & Education & $-0.052 \mathrm{NS}$ \\
\hline 4. & Job experience & $0.043 \mathrm{NS}$ \\
\hline 5. & Training received & $0.259^{* *}$ \\
\hline 6. & Organizational climate & $0.206^{*}$ \\
\hline
\end{tabular}

'*' Significant at 5\% level, '**' Significant at 1\% level, 'NS' Non-significant

Age of teachers showed a negatively significant correlation with the job was positively and significantly correlated with the job performance of teachers. 
Normally, training was provided to enhance teachers ' technical abilities, knowledge, value and culture and soft skills. So, more number of trainings make teachers more effective and up-to-date and make a positive contribution to their job performance. The organizational climate was positively and significantly linked with teachers' job performance. This may be due to the autonomy of teachers and the liberal policies, rules, and communication system of the school, which contributes a positive impact on the job performance of teachers.

\section{CONCLUSION}

From this study it is concluded that more than half of the teachers were in low trained group which means there is lack of advance training and capacity building programmes. It was also seen that training received and organizational climate positively correlated with the job performance of the teachers. Altogether the study points to the need of advanced training, capacity building programmesandastrengthened organizational climate with finest organizational culture with liberal policies, rules, regulations, norms, teachers ' autonomy, and clear hierarchical communication to improve the job performance of the VHSE Agricultural teachers.

\section{REFERENCES}

Getzels, J. M. (1958). Administration as a social process. In. Halpin, A. W. (Ed.) Administrative theory in Education. Midwest Administration- centre, Chicago, $152 \mathrm{p}$.

Kolb, D. A., Rubin, I. M. \& Mclntyre, J. M. (1974). Organizational Psychological: an experiential approach $\left(2^{\text {nd }}\right.$ Ed.). Prentice Hall Inc., New Jersey, 422p.

Sundaraswamy, B. (1987). A study on need achievement and job performance of Assistant Agricultural Officers in Karnataka State. Unpublished Ph.D thesis, Tamil Nadu Agricultural University, Coimbatore, $321 \mathrm{p}$. 